\title{
The sacred versus the secular in UK psychiatry $^{\dagger}$
}

\author{
Rob Poole (1)
}

\begin{abstract}
SUMMARY
I comment on two papers by Koenig and colleagues that advocate the integration of religion into routine psychiatric practice. In my opinion, their selective overview of research, although useful, lacks balance. It omits any mention of the literature on worldwide scandals over child sex abuse (and other abuses of power) perpetrated and facilitated by religious authority within several faith groups. There is no mention of damaging 'religiously informed' treatments such as sexual orientation conversion therapy, which is still practised in the UK despite widespread condemnation. Their recommendations for clinical practice conflate association with causation. They do not offer practice guidance on managing the impact of power imbalances associated with religion in multicultural societies. In summary, despite more than a decade of research and debate, there are still no generally accepted ways of avoiding boundary violations where psychiatrists introduce religion into their clinical practice.
\end{abstract}

\section{Keywords}

Transcultural psychiatry; ethics; education and training; boundary violations; religion.

\section{Background}

Koenig and colleagues present two connected review articles in BJPsych Advances on religion and psychiatry. The first is a selective summary of research (Koenig 2020a). The second makes recommendations for clinical practice (Koenig 2020b). Professor Koenig provoked controversy in 2008 with a paper on similar themes in the Psychiatric Bulletin (Koenig 2008), advocating integration of so-called 'religion/spirituality' into clinical practice. In my opinion, these new articles are best seen in the context of the continuing debate within UK psychiatry (Poole 2019).

There are some uncontroversial points here: patients' faith should be treated with respect as an important part of their lives; religion can be both helpful and unhelpful to mental health; understanding the relationship between symptoms and religious beliefs is sometimes important; and it is legitimate for psychiatrists to work alongside chaplains and other religious leaders. I teach these points to medical students, just as I was taught them in the 1970s. Other aspects of the article are more contentious.

As is commonly the case from advocates of the integration of religion into clinical practice, the articles start with assertions that psychiatry has generally regarded religion as intrinsically pathological. I see little evidence that this is correct, even taking into account the citations here. However, what has worried sceptical clinicians about the growing literature on psychiatry and religion has been lack of clarity about relevant professional boundaries (Poole 2011).

\section{Overview of evidence}

There are gaps in the overview of research on religion and mental health, the most obvious being the omission of some major public concerns. Among these is the effect on mental health, short- and long-term, of child sex abuse perpetrated by priests and other religious figures in the context of their religious role (Lueger-Schuster 2014), often facilitated or covered up by religious authorities (Death 2015). This has proven to be so serious and widespread that it has led to major change in the status of religious authority all over the world, especially the Roman Catholic church. Similarly, there is nothing here about unequivocally harmful religious counselling, such as sexual orientation conversion therapy. This has been condemned as ineffective and unethical by the Royal College of Psychiatrists (2014), but is still advocated and practised by some Christians in the UK (Mosely 2018). These omissions do not invalidate Koenig and colleagues' articles, but they do mean that they lack balance between the benefits and harms of religion.

\section{Recommendations}

Like most recommendations for clinical practice, Koenig and colleagues' clinical guidance is based more on opinion than evidence. The statement in the first article that 'such studies [...] have the potential to contribute evidence for causation' (Koenig 2020a) is appropriately cautious, as the totality of the evidence does not remotely meet the Bradford Hill criteria (Bradford Hill 1965). Their clinical
Rob Poole, MBBS, FRCPsych, is Professor of Social Psychiatry in the Centre for Mental Health and Society, Bangor University, UK. After 21 years as a National Health Service consultant psychiatrist, he became an academic in 2009. His current interests include self-harm, prescribed opioids and professional boundary violations. He has co-authored four books, on clinical skills and on social determinants of mental health, and was awarded the Royal College of Psychiatrists' Lifetime Achievement Award 2017. He declares himself an atheist.

Correspondence Professor Rob Poole. Email: r.poole@bangor.ac.uk

First received 28 Feb 2020 Final revision 16 Apr 2020 Accepted 28 Apr 2020

Copyright and usage The Author(s) 2020

${ }^{\dagger}$ Commentary on... Religion and psychiatry: recent developments in research; and Religion and psychiatry: clinical applications. See this issue. 
guidance, however, is implicitly based on an assumption of causality. This is not an obscure technical point. Much of the literature concerns Christians in the USA, who are the majority in the most religiously active of high-income countries. Religion is a social as well as a spiritual phenomenon, closely linked to ethnicity and class. These are potential confounding factors in most studies. Furthermore, in culturally diverse societies such as the UK, religion has many implications relating to power imbalances and to misuses of power. For example, patients belonging to Muslim minorities might reasonably feel nervous about discussion of their faith with non-Muslim psychiatrists, given prevalent levels of Islamophobia in the UK and USA. These concerns are highly salient to clinical practice, and it is a shame that there is no guidance here about how they might be tackled in practice. In my opinion, the clinical recommendations are not of universal applicability.

\section{Assumptions}

In the article on clinical applications (Koenig 2020b), the authors correctly state that there is little controversy over holistic care that takes into account the patient's religion, where this is the patient's wish. However, I am less comfortable about the related assertion that implies that mental health professionals should assume that religion is benign and beneficial. Both the full literature and experience show that, even among the devout, religion can be more ambiguous than this. The authors do make reference to problems caused by religion, but this is mainly described as 'how patients can use religion neurotically'. It seems possible that sometimes the problem can be with religion and not the patient. It is right that psychiatrists should not seek to undermine their patients' faith, but, in my opinion, they should also be careful not to make assumptions about it.

\section{Moral injury}

The clinical applications article makes reference to moral injury, a problem that has become topical with regard to decisions that healthcare professionals have to make in coping with the current coronavirus pandemic. They make reference to spiritually integrated cognitive processing therapy, a novel intervention for moral injury in the context of post-traumatic stress disorder (PTSD) that is under evaluation (Pearce 2018). This has been developed on the basis of the observation that moral injury and 'spiritual struggles' make it difficult to recover from PTSD and that US military personnel and veterans report high levels of religion/spirituality. I do not criticise the development of explicitly religious forms of therapy, but they are culture bound and therefore not necessarily generally applicable. Many people in the UK do not derive their morality from organised religion and, in any case, it is not clear that moral injury is best understood as a psychiatric disorder per se. Most importantly, a request for a religion- or spirituality-informed therapy does not absolve the therapist of responsibility to be vigilant for inadvertent violations of boundaries.

\section{Conclusion}

Few areas of psychiatry are immune from a mismatch between rhetoric and evidence. In the case of religion, I would be less concerned if it were not for persistent recommendations to change the boundaries of professional practice in a way that I and others believe to be inappropriate. This long debate appears to be far from over and readers will make up their own minds about the salience and validity of these contributions.

\section{Declaration of interest}

None.

An ICMJE form is in the supplementary material, available online at https://doi.org/10.1192/bja.2020. 32 .

\section{References}

Bradford Hill A (1965) The environment and disease: association or causation? Proceedings of the Royal Society of Medicine, 58: 295-300.

Death J (2015) Bad apples, bad barrel: exploring institutional responses to child sexual abuse by Catholic clergy in Australia. International Journal for Crime, Justice and Social Democracy, 4: 94-110.

Koenig HG (2008) Religion and mental health: what should psychiatrists do? Psychiatric Bulletin, 32: 201-3.

Koenig HG, Al-Zaben F, VanderWeele TJ (2020a) Religion and psychiatry: recent developments in research. BJPsych Advances, 26: this issue.

Koenig HG, Peteet JR, VanderWeele TJ (2020b) Religion and psychiatry: clinical applications. BJPsych Advances, 26: this issue.

Lueger-Schuster B, Kantor V, Weindl D, et al (2014) Institutional abuse of children in the Austrian Catholic Church: types of abuse and impact on adult survivors' current mental health. Child Abuse \& Neglect, 38: 52-64.

Moseley C (2018) Ten reasons not to restrict same-sex attraction therapy. Christian Concern (https://christianconcern.com/comment/ten-reasonsnot-to-restrict-same-sex-attraction-therapy). Accessed 27 Feb 2020.

Pearce M, Haynes K, Rivera N, et al (2018) Spiritually integrated cognitive processing therapy: a new treatment for post-traumatic stress disorder that targets moral injury. Global Advances in Health and Medicine, 7: 2164956118759939

Poole R, Higgo R (2011) Spirituality and the threat to therapeutic boundaries in psychiatric practice. Mental Health, Religion \& Culture, 14: 19-29.

Poole R, Cook CCH, Higgo R (2019) Psychiatrists, spirituality and religion. British Journal of Psychiatry, 214: 181-2.

Royal College of Psychiatrists (2014) Royal College of Psychiatrists Statement on Sexual Orientation (Position Statement PSO2/2014). Royal College of Psychiatrists. 